\title{
Rheological, textural and sensorial properties of mayonnaise fortified with Asian sea bass bio-calcium
}

\author{
Ima Wijayanti ${ }^{1}$, Thummanoon Prodpran ${ }^{2}$, Pornsatit Sookchoo $^{3}$, Nilesh Nirmal ${ }^{3}$, Bin \\ Zhang $^{3}$, Amjad Balange ${ }^{3}$, and Soottawat Benjakul ${ }^{3}$ \\ ${ }^{1}$ Prince of Songkla University - Hat Yai Campus \\ ${ }^{2}$ Prince of Songkla University \\ ${ }^{3}$ Affiliation not available
}

January 31, 2022

\begin{abstract}
Fortification of Asian sea bass bone bio-calcium (ASBC) at different levels (0-10\%) into mayonnaise was carried out. Firmness, consistency and cohesiveness of mayonnaise were augmented with increasing ASBC levels $(\mathrm{P}<0.05)$. ASBC raised lightness $\left(\mathrm{L}^{*}\right)$ and total color difference $\left(\right.$ ? $\left.\mathrm{E}^{*}\right)$, but decreased $\mathrm{a}^{*}$ and $\mathrm{b}^{*}$-values of mayonnaise in a dose dependent manner $(\mathrm{P}<0.05)$. Higher G', G', viscosity and shear stress value were observed in mayonnaise sample added with ASBC. However, lower acceptability was attained when mayonnaise was added with ASBC at level higher than $2.5 \%$ due to fishy odor and grittiness perceived by panelists. Ultrasonicated ASBC (U-ASBC) was prepared using pulse mode at $70 \%$ amplitude for different times ( 5,10 and $15 \mathrm{~min}$ ) in the presence of hexane. Based on acceptability, mayonnaise added with U-ASBC using ultrasonication time of $15 \mathrm{~min}$ was selected. Reduced particle size with lowered volatile compounds was attained in U-ASBC powder than that of ASBC. Mayonnaise added with 7.5\% U-ASBC (M-UBC-7.5) had higher viscosity with lower creaming and thermal creaming index $(\mathrm{P}<0.05)$ compared to the control and that added with 2.5\% ASBC $(\mathrm{M}-\mathrm{BC}-2.5)$. Optical microscopic images showed that denser and smaller droplet size was observed for M-BC-2.5 and M-UBC-7.5 than control. The lowest moisture, fat and carbohydrate contents were attained for M-UBC-7.5 with the higher protein, ash and calcium content $(\mathrm{P}<0.05)$, compared to control and M-BC-2.5. Fortification of mayonnaise with ASBC at $2.5 \%$ or U-ASBC at $7.5 \%$ could increase calcium content by 54 or 174 times, respectively, without any sensorial changes.
\end{abstract}

\section{Hosted file}

Text.docx available at https://authorea.com/users/458243/articles/554827-rheologicaltextural-and-sensorial-properties-of-mayonnaise-fortified-with-asian-sea-bass-biocalcium 

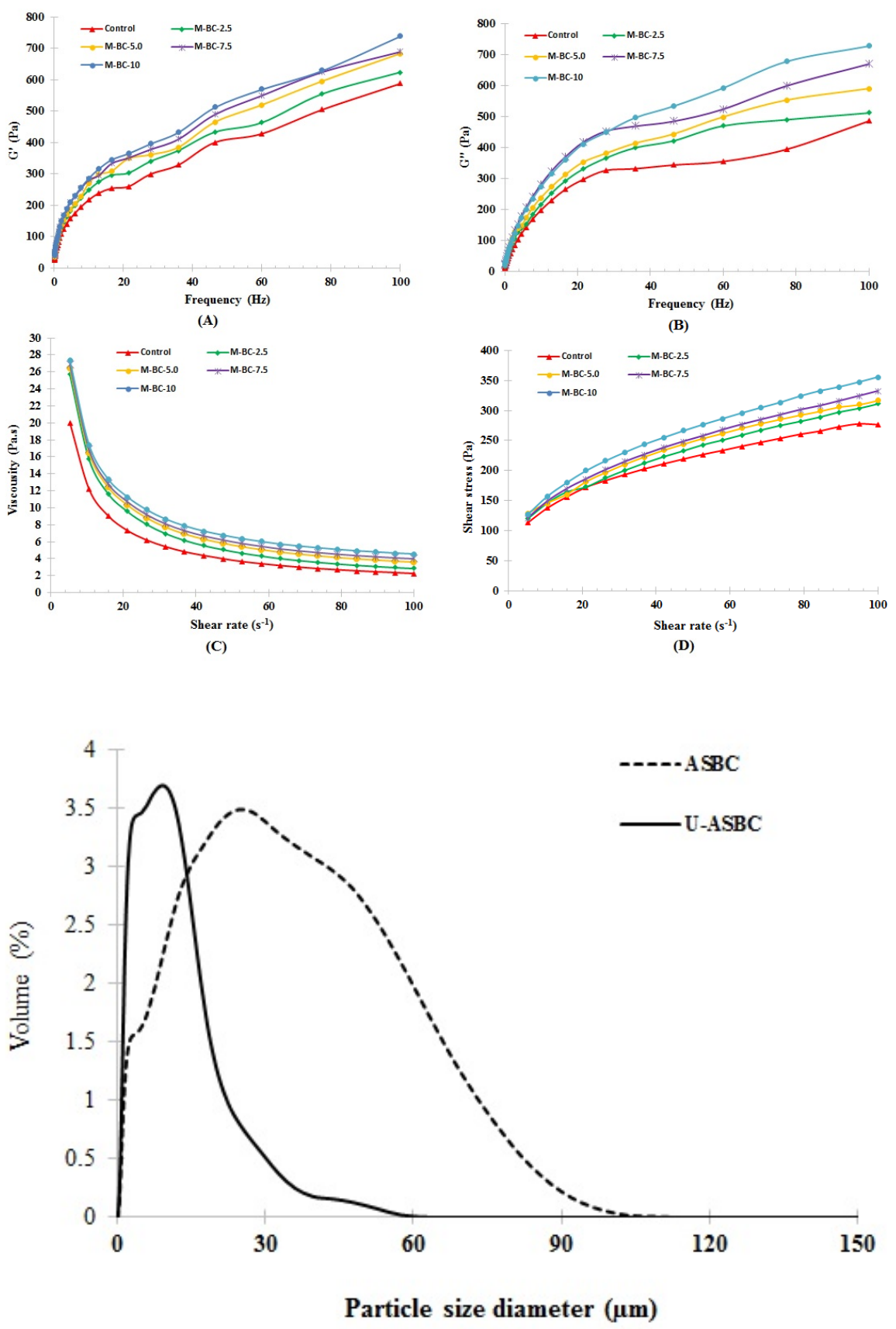

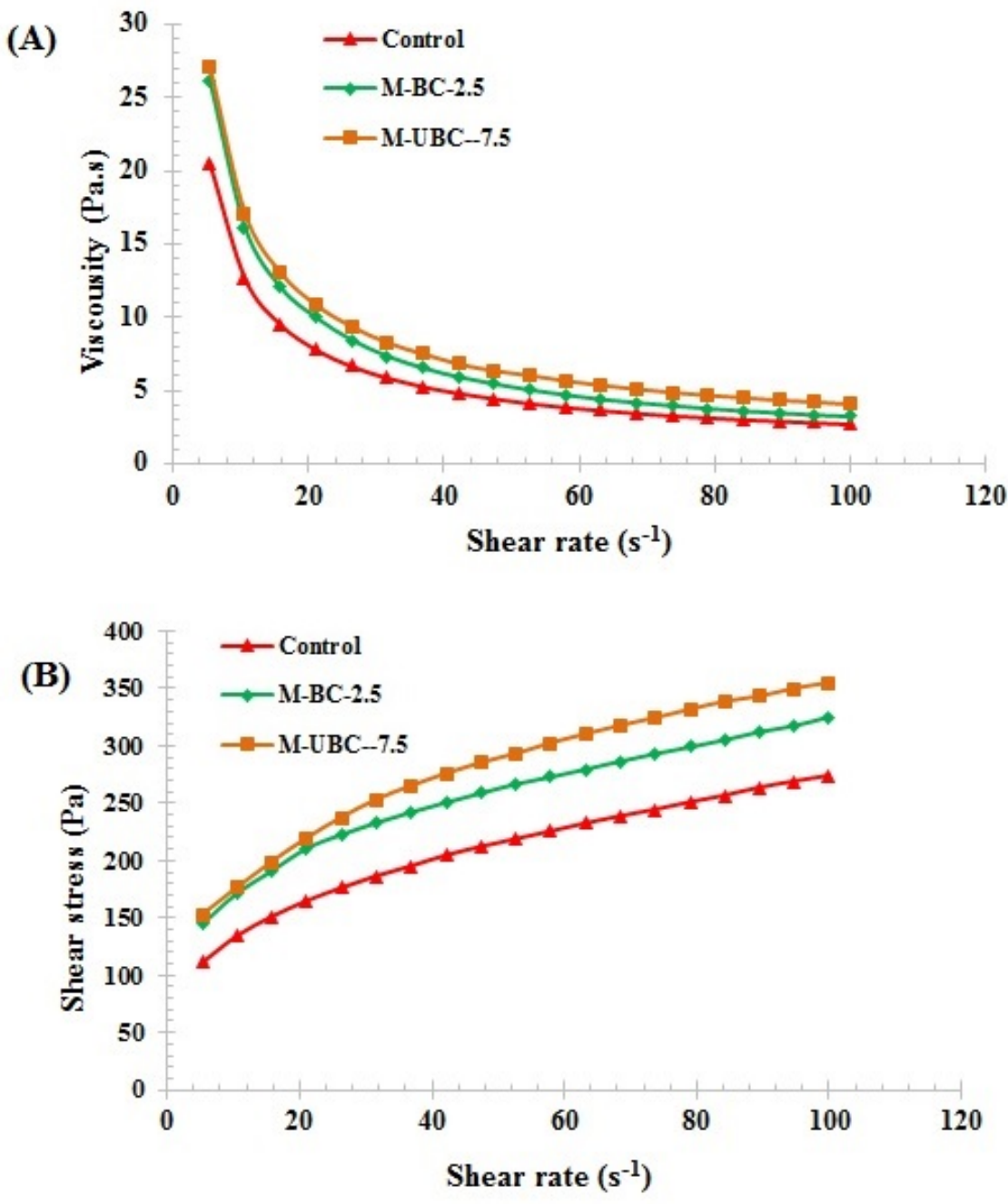

(A)

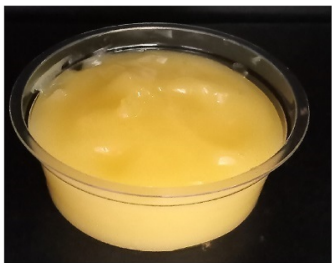

Control

(B)

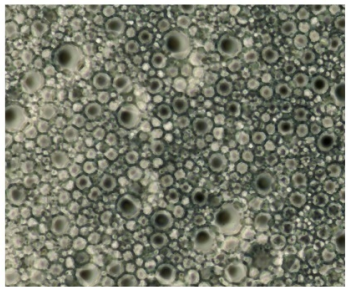

Control

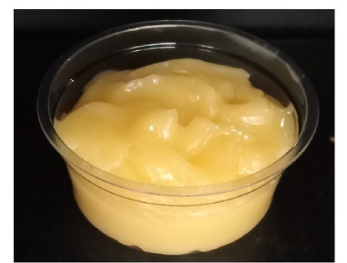

M-BC-2.5

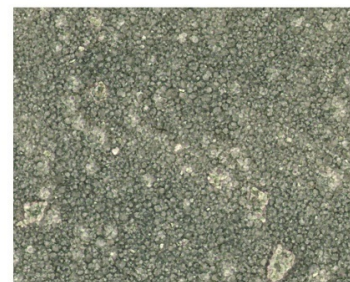

M-BC- 2.5

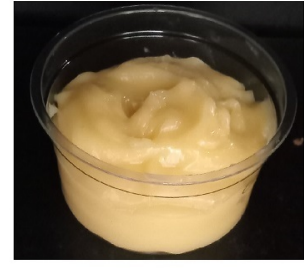

M-UBC-7.5

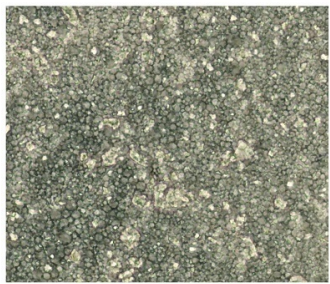

M-UBC-7.5 